\title{
RELATIONSHIP OF GRIT AND OPTIMISM AMONG SPORTSPERSONS
}

\author{
Manasa P \\ Research Scholar \\ Jain University, Bangalore, \\ Karnataka, India
}

\begin{abstract}
The aim of this paper is to study the relationship between Grit and being optimistic in sports person. Grit is defined as non-cognitive trait based on an individual's passion for a particular long-term goal or end state, coupled with a powerful motivation to achieve their respective objective. In the recent days, grit has been used in sports to make a good player to the best player. There has been significant evidence to see how improving grit has helped people achieve success. Grit has always emphasized on the components like passion or perseverance. This study will see its relationship with positivity or optimistic belief. The study was conducted on a group of 30 subjects. All the subjects were from different sports. They were assessed the Grit and also positivity using a Grit scale and Life Orientation scale. The results showed that there was a positive relationship between the grit and positivity. In other words, it was seen that sports persons who were grittier were also the ones who had positive outlook towards the life.
\end{abstract}

Keywords-Sports, Grit, Positivity

\section{INTRODUCTION}

Psychological skills are very critical for athletes or sports person at any level of their performance. Research has demonstrated that more than the physical aspect, it is the "Mental toughness", which is an utterly crucial component in the preparation of success of an athlete. Sports has always been a very integral part of holistic human development and in the past there have been assumptions that a lot of skills are genetically based or acquired in early lives. But the research and experiments have shown evidence that skills can be acquired by training. Like physical skills, psychological skills/factors can be identified and honed as they play a critical role in their performance.

Grit has been a topic of interest from the time Angela Duckworth (2016) spoke about it and introduced to the world a multifaceted encompassing passion and perseverance. She beautifully elaborates on it by highlighting that "Grit in a word, is stamina. But it's not just stamina in your effort. It's also stamina in your direction, stamina in your interests. If you are working in different things but all of them very hard, you're not really going to get anywhere. You'll never become an expert". She further went on to emphasize about how not only Talent plays an important role in the field of success, but Grit also plays a prominent factor in influencing success.

The concept of Grit started off from the military camp and then continued to the education setting. In the studies, Duckworth(2016) in her book mentioned that she found out that the ones who scored higher in grit scale were the ones who were also successful in their future and also they had more chances of long term success, rather than the ones who had got much lesser score in the grit scale. There have been a lot of research conducted on how to identify the grittier ones in the early stage, and give them the best training, hence help them achieve their best.

Achieving the best also comes from the positivity which fuels the belief in oneself, beautifully captured in the concept of Optimism. As Muhammad Ali, (1974), rightly puts the essence of importance of optimism in sports in this quote, "Champions aren't made in gyms. Champions are made from something they have deep inside them- A desire, a dream, a vision. They have to have the skill and the will. But the will must be stronger than the skill".

Optimism is hopefulness and confidence about the future or the success of something. It could also be said as a mental attitude reflecting a belief or a hope that the outcome of some specific endeavor or outcomes in general will be positive or favorable and also desirable. We call a person as an optimist when he sees a glass of water as half-filled rather than seeing it as half empty. Being optimistic as an athlete is very important because, a person with a positive outlook towards life tends to be more persistent and committed during the action phase of any game. These people tend to feel to have a control over their play. They are the ones who believe that they are a good player and hence tend to play better in the matches. And also since they have a control on their performance, they will not blame of the luck or any other factors when they do not perform well. (Martin-Krumm, Sarrazin, Peterson, \& Famose, 2003; Seligman, NolenHoeksema, Thornton, \& Thornton, 1990)

Psychological Factors like grit and optimism are thus the extra something that separates the most successful people from the rest. Grit being the "passion, perseverance, and stamina that one must channel in order to stick to our dreams until they become a reality". Thus, both these factors have been demonstrated as that which separates the successful people 


\section{International Journal of Engineering Applied Sciences and Technology, 2020 Vol. 5, Issue 4, ISSN No. 2455-2143, Pages 601-605 \\ Published Online August 2020 in IJEAST (http://www.ijeast.com)}

from the rest of the crowd. There have been a lot of studies done regarding their contribution to success in various fields. In this present research, the researcher has studied the relationship between the Grit and Optimism. The research mainly delves into the type of relationship between Grit and Optimism. In other words, this study examines if Grittier people are more optimistic in their lives. Since grit and optimism are closely related to the success of their performance, knowing their relationship would help to know where they stand and thus help them to improve these factors in them and get the best performance.

Review of Literature

The review of related studies has given an empirical background on the present research. It highlights various research related to Grit and sports and also the importance of being Optimistic as a sports person. Based on the gaps found in the previous literature findings, the objective of this study focused on bridging those gaps through further understanding of the relationship between the two above mentioned variables. There has been past research conducted in the fields of grit and optimism, respectively but very few have focused on studying the relationship between them and that too specifically.

A case study conducted by Morgan (2016) focused to see the difference of Grit in a student and athlete performance in University of Mexico. This study highlighted how the grit level of the students in academics is different from that of the grit levels of the athletes in sports. The purpose of this study was to investigate the relationship between grit and studentathlete academic and sport performance. An exploratory study was conducted using a case study methodology, utilizing both quantitative and qualitative research. The results indicated a positive correlation between student-athlete grit level and informant grit report, which signified that student-athlete were consistently rating their grit higher than their coach rated it. Also, it was seen that, grit does not account for more predictive value of college academic performance than traditional factors of academic success of college studentathletes. Lastly, the major findings of the study were that 1) grit increases individual development and sport performance, and 2) team culture is enhanced by increased individual grit.

Another research conducted by Matthews, Kelly, Maddi, Villarreal and White (2012) in United States Military Academy in West on Grit in terms of Perseverance and Passion for Long-Term Goals. As the importance of intellectual talent to achievement in all professional domains is well established, this study highlighted the individual differences that predict success. The authors tested the importance of a non-cognitive trait: grit. Defined as perseverance and passion for long-term goals, grit accounted for an average of $4 \%$ of the variance in success outcomes, including educational attainment among 2 samples of adults, grade point average among Ivy League undergraduates, retention in 2 classes of United States Military Academy, West Point, cadets, and ranking in the National Spelling Bee.
It was seen that Grit did not relate positively to IQ but was highly correlated with Big Five Conscientiousness. Grit nonetheless demonstrated incremental predictive validity of success measures over and beyond IQ and conscientiousness. Collectively, these findings suggested that the achievement of difficult goals entails not only talent but also the sustained and focused application of talent over time.

A Meta-analysis was done by Credé, Tynan and Harms (2017) from Iowa state university and University of Alabama on the Grit Literature. The paper highlighted how Grit had been presented as a higher order personality trait that is highly predictive of both success and performance and distinct from other traits such as conscientiousness. This paper provided a meta-analytic review of the grit literature with a particular focus on the structure of grit and the relation between grit and performance, retention, conscientiousness, cognitive ability, and demographic variables. The results indicated that the higher-order structure of grit was not confirmed, that grit is only moderately correlated with performance and retention, and that grit is very strongly correlated with conscientiousness. They also find that the perseverance of effort facet has significantly stronger criterion validities than the consistency of interest facet and that perseverance of effort explains variance in academic performance even after controlling for conscientiousness. In aggregate the results suggested that interventions designed to enhance grit may only have weak effects on performance and success, that the construct validity of grit is in question, and that the primary utility of the grit construct may lie in the perseverance facet.

A study conducted by Nicholls, Polman, Levy and Backhouse (2008) examined the Mental toughness, Optimism, Pessimism and coping among the athletes. The purpose of this paper was to explore the relationship between: (a) mental toughness and coping, (b) mental toughness and optimism, and (c) coping and optimism. Participants were 677 athletes aged between 15 and 58 years. The results of the study showed that mental toughness correlated significantly with 8 of the 10 coping subscales and optimism. In particular, higher levels of mental toughness were associated with more problem or approach coping strategies (mental imagery, effort expenditure, thought control, and logical analysis) but less use of avoidance coping strategies (distancing, mental distraction, and resignation). Eight coping subscales were significantly correlated with optimism and pessimism. In conclusion, the relationships observed in this study emphasize the need for the inclusion of coping and optimism training in mental toughness interventions.

Thus, the above researches talk about how important Grit has been in performance and also how Optimism will improve mental toughness. This shows that both the variables Grit and Optimism are very crucial concepts and determine a lot about the performance.

However, there is paucity of research with respect to Grit in terms of sports. Thus, this research paper will examine the relationship between the individual's grit and their optimistic 


\section{International Journal of Engineering Applied Sciences and Technology, 2020 \\ Vol. 5, Issue 4, ISSN No. 2455-2143, Pages 601-605 \\ Published Online August 2020 in IJEAST (http://www.ijeast.com)}

outlook towards life in the domain of sports. This research aims to fill in the gap in literature by helping to know the relationship between the most important variables and also make place for further studies which could explore into the same. In other words, help the upcoming researchers to develop a training program that would inculcate the variables and hence see the results in their performance.

\section{METHODOLOGY}

\section{Methodology}

The objective of the study is to find out the relationship between Grit and Optimism among the sports persons.

Hypothesis: Based on the paucity of the literature review regarding the relationship of grit and optimism with respect to the domain of sports, the null hypothesis was constructed:

- There is no significant relationship between the Grit and optimism among the sports persons.

Variables: Grit- The term grit is the very essence of sports through anecdotes and metaphors of discipline, perseverance, and triumph, also serves as a valid and reliable measure of success throughout diverse life pursuits. Duckworth, Peters, Matthews, and Kelly (2007) define grit as "perseverance and passion towards long term goals". Grit is no longer left to the annals of sport autobiographies or of subjective fairytales of hard work and pre-game pep talks because it can now be objectively measured with the Grit Scale.

Optimism- Optimism is a construct that has undergone much examination in the past two decades (Marshall \& Lang, 1990; Scheier \& Carver, 1987). It has been defined as a general expectancy that good things will happen (Scheier \& Carver, 1985, 1987). These general expectancies, also referred to as dispositional optimism, affect not only one's beliefs and emotions, but also one's decisions related to persistence in times of adversity. Someone who is an optimist is more likely to see desirable outcomes as attainable and is less likely to give up when adversity strikes (Peterson, 2000; Smith, Pope, Rhodewalt, \& Poulton, 1989; Scheier \& Carver, 1987). In addition, an optimist is not likely to perceive situations as threatening or to worry about upcoming events (Kavussanu \& McAuley, 1995).

Tools: Grit and Optimism was measured with the help of two questionnaires. Short Grit Scale by Duckworth and Quinn (2009) was used to measure grit. The scale comprises of 8 items and is a likert scale with five point responses from Not at all like me to Very much like me. Optimism was measured using Life orientation scale (Scheier, Carver, \& Bridges, 1994). It comprised of 10 statements and had five point scales from Strongly Agree to Strongly Disagree.

Participants: The sample for the present study comprised of 30 sports persons aged from 15 to 28 from Bangalore. The sample comprised of sportsmen actively engaged in the games of Cricket, Football, Badminton and Kabbadi. These sports persons were the ones who had been into sports in either regional or national levels. The technique used for sampling was convenient sampling.

Procedure: The subjects were first informed about the purpose for the study and informed consent was duly taken. They had been told that their responses will solely be used for research purpose and thus assured of confidentiality. The sample was provided with the questionnaires and requested to fill in their responses. The data was collected through the academies of various sports.

Statistical Analyses: Descriptive statistics i.e. Means, Standard deviations (SDs) were calculated. Pearson's product moment correlation coefficient was used to ascertain the relationship between Grit and Optimism.

\section{RESULTS AND DISCUSSION}

All the data that was collected was scored accordingly. After scoring, the data was subjected to Normal distribution test and means and standard deviation was found. After getting the scores to be normally distributed, the scores were correlated. The statistics used was Pearson's product moment correlation coefficient. Correlation refers to the relationship between two variables and thus statistics help to quantify this relationship and measure its direction. The value of the correlation coefficient, denoted as $\mathrm{r}$, ranges from -1 to +1 , which gives the strength of the relationship and whether the relationship is negative or positive. When the value of $r$ is greater than zero, it is a positive relationship; when the value is less than zero, it is a negative relationship. A value of zero indicates that there is no relationship between the two variables. Since the study had two variables and both had to be related to each other, correlation was used.

Table 1

Mean and Standard deviation for Grit and Optimism

$\begin{array}{lcc} & \text { Grit } & \text { Optimism } \\ \text { Mean } & 37.26 & 23.6 \\ \text { Standard Deviation } & 6.30 & 3.88\end{array}$

Table 2

Correlations between the Measures Grit and Optimism

$\begin{array}{lcc}\text { Measure } & \text { Grit } & \text { Optimism } \\ \text { Grit } & & 0.32\end{array}$

Optimism

The Table 1 shows the mean and the standard deviation. The variable Grit has a mean of 37.26 and the standard 


\section{International Journal of Engineering Applied Sciences and Technology, 2020 \\ Vol. 5, Issue 4, ISSN No. 2455-2143, Pages 601-605 \\ Published Online August 2020 in IJEAST (http://www.ijeast.com)}

deviation is 6.30. The variable Optimism has a mean of 23.6 and the standard deviation is 3.88 .

The Table 2 shows the correlation coefficient for scores on Grit and Optimism. The correlation coefficient was found to be 0.14 . The score is non significant. There is a positive relationship between the two variables. In other words, it means that a high score in Grit will also have a high score on Optimism.

The above results states that "There is a positive relationship between the Grit scores and optimism among the sports persons" and thus rejects the Null hypothesis which stated that "There is no significant relationship between the Grit scores and optimism towards life among the sports persons". Thus, the results of this study show that the sports people who are grittier are also the ones who are more optimistic. And this leads to the fact that to improve the performance of the sports persons, it is very crucial to train them in improving the grit level which will make them have positive outlook towards the game as a whole, thus helping them to give their best to the game.

\section{LIMITATIONS}

There are few limitations that could be used as gaps and developed into future studies. The first one would be the size of the sample. The size is too small to be generalized to whole of the population. The second limitation is the demography. The sample was collected only from Bangalore and due to paucity of time, included sportspersons from variety of sports. So, there could be variations if it was from a much larger population from different demography as well. The third limitation would be the study could have been more effective if there was also interviews with the sample to know why they agreed on few statements and also disagreed on few. There could have been a deeper understanding of why grittier players are optimistic. These would be few limitations of the study.

\section{V.CONCLUSION}

This research titled "A quantitative study on sports persons to see the relationship between their levels of Grit and optimism" had an objective to find out the relationship between Grit and Optimism among the sports persons. The sample size was 30 who were into sports and belonged to the age group of 15 to 29 and were from Bangalore. The data was collected by using two scales, one for Grit which is Grit scale and the other one to measure the optimism which was measured by Life Orientation scale. The statistical method correlation was used to see the relationship between the variables. The results showed that there was a positive relationship between the variables Grit and Optimism, which indicates that a person who has a higher grit score tends to optimistic as well.
The study could be used for further research to see how improving the grit the grit scores can lead to increase in optimism, hence help the player enhance the performance. The study will also help the coach or the managements to get players who are already grittier and get the best out of them as they would be more positive to improve their performance. It is always easier and more efficient to train the ones who are more optimistic, as they would always be looking for to get better and they are the ones who are willing to give their best to the game.

\section{REFERENCE}

[1] B. Corona, M. Nakano, H. Pérez, "Adaptive Watermarking Algorithm for Binary Image Watermarks", Lecture Notes in Computer Science, Springer, pp. 207-215, 2004.

[2] Credé, M., Tynan, M. C., \& Harms, P. D. (2017). Much ado about grit: A meta-analytic synthesis of the grit literature. Journal of Personality and Social Psychology, 113(3), 492.

[3] Duckworth, A. L., \& Quinn, P. D. (2009). Development and validation of the Short Grit Scale (GRIT-S). Journal of Personality Assessment, 91(2), 166-174.

[4] Duckworth, A. (2016). Grit: The power of passion and perseverance. Simon and Schuster.

[5] Duckworth, A. L., Peterson, C., Matthews, M. D., \& Kelly, D. R. (2007). Grit: perseverance and passion for long-term goals. Journal of Personality and Social Psychology, 92(6), 1087.

[6] Gaudreau, P., \& Blondin, J. P. (2004). Differential Associations of Dispositional Optimism and Pessimism With Coping, Goal Attainment, and Emotional Adjustment During Sport Competition. International Journal of Stress Management, 11(3), 245.

[7] Joseph, A. I. (2009). The role of grit in predicting performance in collegiate athletes. Unpublished Doctoral dissertation, ProQuest Information \& Learning.

[8] Kavussanu, M., \& McAuley, E. (1995). Exercise and optimism: are highly active individuals more optimistic?. Journal of Sport and Exercise Psychology, 17(3), 246-258.

[9[ Maddi, S. R., Matthews, M. D., Kelly, D. R., Villarreal, B., \& White, M. (2012). The role of hardiness and grit in predicting performance and retention of USMA cadets. Military Psychology, 24(1), 19.

[10] Marshall, G. N., \& Lang, E. L. (1990). Optimism, selfmastery, and symptoms of depression in women professionals. Journal of personality and social psychology, 59(1), 132.

[11] Martin-Krumm, C. P., Sarrazin, P. G., Peterson, C., \& Famose, J. P. (2003). Explanatory style and resilience after sports failure. Personality and individual differences, 35(7), 1685-1695. 


\section{International Journal of Engineering Applied Sciences and Technology, 2020 \\ Vol. 5, Issue 4, ISSN No. 2455-2143, Pages 601-605 \\ Published Online August 2020 in IJEAST (http://www.ijeast.com)}

[12] Morgan, T. P. (2016). Grit and student-athlete performance: A case study. Mexico: ProQuest Dissertations Publishing. Retrieved from https://search.proquest.com/openview/8c529e25434dbe13 b42d2de5fb7f95b3/1?pqorigsite $=$ gscholar $\&$ cbl $=18750 \&$ diss $=y$

[13] Nicholls, A. R., Polman, R. C., Levy, A. R., \& Backhouse, S. H. (2008). Mental toughness, optimism, pessimism, and coping among athletes. Personality and Individual Differences, 44(5), 1182-1192.

[14] Norlander, T., \& Archer, T. (2002). Predicting performance in ski and swim championships: Effectiveness of mood, perceived exertion, and dispositional optimism. Perceptual and Motor Skills, 94(1), 153-164.

[15] Peterson, C., Park, N., \& Seligman, M. E. (2013). Orientations to happiness and life satisfaction: The full life versus the empty life. In A. D. Fave (Ed.), The Exploration of Happiness (pp. 161-173) Springer, Dordrecht.

[16] Peterson, C., Ruch, W., Beermann, U., Park, N., \& Seligman, M. E. (2007). Strengths of character, orientations to happiness, and life satisfaction. The Journal of Positive Psychology, 2(3), 149-156.

[17] Peterson, C. (2000). The future of optimism. American psychologist, 55(1), 44.

[18] Seligman, M. E., Nolen-Hoeksema, S., Thornton, N., \& Thornton, K. M. (1990). Explanatory style as a mechanism of disappointing athletic performance. Psychological Science, 1(2), 143-146.

[19] Scheier, M. F., Carver, C. S., \& Bridges, M. W. (1994). Distinguishing optimism from neuroticism (and trait anxiety, self-mastery, and self-esteem): a reevaluation of the Life Orientation Test. Journal of personality and social psychology, 67(6), 1063.

[20] Scheier, M. E., \& Carver, C. S. (1987). Dispositional optimism and physical well-being: The influence of generalized outcome expectancies on health. Journal of personality, 55(2), 169-210.

[21] Scheier, M. F., \& Carver, C. S. (1985). Optimism, coping, and health: assessment and implications of generalized outcome expectancies. Health psychology, 4(3), 219.

[22] Sheard, M., \& Golby, J. (2006). Effect of a psychological skills training program on swimming performance and positive psychological development. International Journal of Sport and Exercise Psychology, 4(2), 149-169.

[23] Smith, T. W., Pope, M. K., Rhodewalt, F., \& Poulton, J. L. (1989). Optimism, neuroticism, coping, and symptom reports: An alternative interpretation of the Life Orientation Test. Journal of Personality and Social Psychology, 56(4), 640.

[24] Venne, S. A., Laguna, P., Walk, S., \& Ravizza, K. (2006). Optimism levels among collegiate athletes and non-athletes. International Journal of Sport and Exercise Psychology, 4(2), 182-195.

[25] Von Culin, K. R., Tsukayama, E., \& Duckworth, A. L. (2014). Unpacking grit: Motivational correlates of perseverance and passion for long-term goals. The Journal of Positive Psychology, 9(4), 306-312. 